\title{
RESEARCH
}

\section{Developing a Framework of Relationships Among Noncognitive Factors in Doctor of Pharmacy Students' Academic Performance}

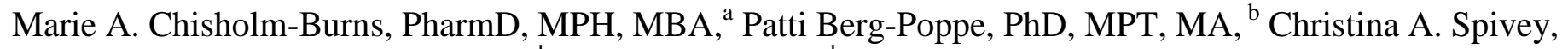 \\ $\mathrm{PhD},{ }^{\mathrm{a}}$ Joy Karges-Brown, EdD, MS, ${ }^{\mathrm{b}}$ Anne Pithan, DNP ${ }^{\mathrm{b}}$ \\ ${ }^{a}$ University of Tennessee Health Science Center, College of Pharmacy, Memphis, Tennessee \\ ${ }^{\mathrm{b}}$ University of South Dakota, School of Health Sciences, Vermillion, South Dakota
}

Corresponding Author: Marie A. Chisholm-Burns, The University of Tennessee Health Science Center, College of Pharmacy, 881 Madison Ave, Suite 264, Memphis, TN 38163. Tel: 901-448-6036. Email: $\underline{\text { mchisho3@uthsc.edu }}$

Submitted February 19, 2021; accepted May 21, 2021; ePublished June 2021

Objective. To develop a framework of the effects of select noncognitive factors (grit, perceived stress, internal locus of control, and select Big Five Personality Traits) on pharmacy students' academic performance.

Methods. A survey measuring select noncognitive factors was administered to two cohorts of first-year pharmacy (P1) students (entering classes of 2019 and 2020, n=374) during fall orientation. Demographics, pre-pharmacy GPA, and P1 fall semester GPA were collected from student records. Structural equation modeling (SEM) was conducted to assess the proposed framework.

Results. Academic performance was directly influenced by students' $(\mathrm{n}=367 ; 98.1 \%)$ perceived stress and neuroticism and indirectly influenced by internal locus of control and neuroticism (via perceived stress as mediator). Neuroticism has a complex relationship in the models as it was directly and positively associated with academic performance, and also indirectly contributed to decreased academic performance via a positive association with perceived stress. Squared multiple correlations indicated $13 \%$ and $9 \%$ of the variance in academic performance in the first final model (academic performance measured by pre-pharmacy GPA and P1 fall GPA) and second final model (academic performance measured by P1 fall GPA), respectively, were explained by the predictor variables.

Conclusion. Evidence provided by SEM supports select noncognitive factors, namely perceived stress, neuroticism, and internal locus of control, have direct and indirect effects on the academic success of P1 students. The model variances of $9 \%$ and $13 \%$ represent $36 \%$ to $52 \%$ of the predictive value of the most commonly accepted cognitive measures used to determine students' potential for academic success.

Keywords: academic performance, big five personality traits, grit, locus of control, resilience

\section{INTRODUCTION}

Academic success is a major concern for pharmacy students and their families as well as educational institutions. Improved understanding of factors predictive of academic performance is vital to developing strategies and interventions to promote student success. Meagher et al. ${ }^{1}$ noted the cognitive measures of pre-pharmacy grade point average (GPA) and Pharmacy College Admissions Test (PCAT) combined explained approximately 25\% of the variance in first-year pharmacy (P1) GPA. As Novovic et al. ${ }^{2}$ summarized, although cognitive measures such as GPA and PCAT are "somewhat predictive of success during pharmacy school, they still do not explain the majority of variance observed in student achievement."

A range of noncognitive attributes, described by Stoffel and $\mathrm{Cain}^{3}$ as "those skills associated with motivation, attitude, and temperament rather than intellect," exist and may play a role in student performance. Such attributes include (but are not limited to) self-perceptions or constructs, self-control, work and social behaviors (eg, perseverance), attitude or emotion toward a task, and personality traits. ${ }^{4-8}$ Given this broad scope, a focus on select factors reflective of the diversity of noncognitive attributes is appropriate. Previous studies indicate the select noncognitive factors of grit, locus of control, the Big Five Personality Traits, and perceived stress may be associated with learning and academic success among health professions students. ${ }^{9-20}$ For example, studies conducted by Munro ${ }^{19}$, Ofori and Charlton ${ }^{14}$, and Webb et al. ${ }^{20}$, found higher internal locus of control (or perceptions of control over one's life) was associated with better academic performance among nursing and medical students. Among 16 studies specifically in pharmacy 
students, inconsistent relationships between these noncognitive factors and academic performance were generally noted (Table 1). ${ }^{15,17,21-34}$ For example, Gruenberg et al. ${ }^{26}$ found grit (ie, persistence in and passion for a task/goal) was not associated with either GPA or matching to a postgraduate pharmacy residency program, while other studies found significant associations between increased grit, residency matching, and higher GPA. ${ }^{15,28}$ Studies of the Big Five Personality Traits (the dimensions of personality defined as agreeableness, conscientiousness, extraversion, neuroticism, and openness) were likewise inconsistent, although inverse associations were noted between academic outcomes and the traits of agreeableness, extraversion, and neuroticism. ${ }^{22,29,33,34}$ Although less well-studied than in medical students, studies examining perceived or self-reported stress (ie, emotional strain) among pharmacy students were typically consistent, with all but two of eight studies reporting increased stress was associated with poorer academic performance among pharmacy students. ${ }^{17,21,24,25,27,30-32}$

Due to the high cost of pharmacy school, risk of attrition and emerging emphasis placed on noncognitive attributes and skills in Doctor of Pharmacy (PharmD) curricula, academic pharmacy leaders must develop a better understanding of these noncognitive factors, their relationship with academic success, and potential strategies to utilize noncognitive factors to limit student attrition. ${ }^{35}$ While a number of studies examined the association between academic success and individual factors, a literature search (PubMed and Scopus, years unlimited) failed to produce a framework of the relationships among grit, perceived stress, locus of control, select Big Five Personality Traits, and pharmacy students' academic performance. Therefore, the purpose of this study was to develop such a framework, as confirmed through structural equation modeling (SEM).

\section{METHODS}

As most attrition and poor academic performance occur early in the didactic portion of the PharmD curriculum (D. Havrda, personal communication, December 11, 2019), this study focused on academic success in the fall semester of the first year of pharmacy school. ${ }^{36-39}$ A survey composed of instruments measuring the noncognitive factors of interest was administered to two cohorts of first-year pharmacy (P1) students at the University of Tennessee Health Science Center (UTHSC) College of Pharmacy. All P1 students entering in fall $2019(n=204)$ and fall $2020(n=177)$ were eligible to participate. Survey administration was conducted during first-year fall orientation in 2019 and 2020. The study was approved by the UTHSC Institutional Review Board.

Figure 1 depicts the proposed framework (model) being tested, derived from knowledge gained from previously described studies of the select noncognitive factors influencing academic performance of health professions students. Variables included in the proposed model are defined as follows:

- Big Five Personality Traits: the five "primary dimensions of individual differences in personality." 40 Individuals with high levels of agreeableness are courteous and cooperative while those with low levels are antagonistic and prejudiced. ${ }^{41,42}$ Individuals with high levels of extraversion are enthusiastic, sociable, and communicative while those with low levels are withdrawn and reserved. ${ }^{41,42}$ Individuals with high levels of neuroticism are nervous, anxious, and insecure while those with low levels are unemotional and independent. ${ }^{41,42}$ For the sake of parsimony due to SEM stability, conscientiousness and openness were not included in the proposed model due to lack of evidence regarding their relationships to academic outcomes in pharmacy students. ${ }^{9}$

- Grit: "perseverance and passion for long-term goals.",43

- Locus of Control: "the degree to which people believe that they have control over the outcomes or events in their lives, as opposed to external forces beyond their control.",44

- Perceived Stress: "feelings about the uncontrollability and unpredictability of one's life, how often one has to deal with irritating hassles, how much change is occurring in one's life, and confidence in one's ability to deal with problems or difficulties." ${ }^{45}$ Based on the pervasive underlying influence of perceived stress on individuals' daily lives, in the proposed model we hypothesize perceived stress mediates the effects of grit, locus of control, and the select Big Five Personality Traits on academic performance (mediation is defined by Hopwood ${ }^{46}$ as "a case in which a third variable is a pathway for the effect of a predictor on an outcome") ${ }^{47}$

- Academic Performance: P1 fall GPA and pre-pharmacy GPA were selected as indicators for academic performance because (a) pre-pharmacy GPA, based on prerequisite undergraduate coursework primarily comprised of science and math courses (Appendix A), has been demonstrated to play a role in academic success in pharmacy school; and (b) P1 fall GPA, comprised of courses in Appendix B, is a measure of early pharmacy school performance. ${ }^{1,38,48-51}$

To test the proposed model, valid and reliable instruments previously utilized in pharmacy and other health professions student populations were selected to measure the select noncognitive factors. ${ }^{15,17,25,31,52}$ Cronbach's alphas 
were calculated to determine internal consistency (reliability) of the instruments. Cronbach's alpha of .7 or greater is considered acceptable, with at least .5 considered "minimally adequate. ${ }^{, 53,54}$ Other data were collected from student records, including demographics (gender and race/ethnicity), pre-pharmacy GPA, and P1 fall GPA, and entered in a study database. A cross-check for accuracy was conducted of a random sample of data entered into the database as a quality control measure.

The eight-item Short Grit Scale (Grit-S) utilizes a 5-point Likert scale to assess level of response to each item, ranging from 1= "Not like me at all" to 5= "Very much like me" (note, the total Grit-S, rather than its two subscales, was the focus of this study). ${ }^{55}$ The Grit-S includes reverse-scored items in which the wording of these four items was in the opposite direction of the wording of the remaining four items (ie, negatively-worded [less grit] vs. positively-worded [more grit], respectively). Scores of these four items are "reversed" to be consistent with the directionality of the remaining four items, for example, a score of 1 is changed to 5. The eight item scores are averaged and total scores range from 1 to 5, with higher scores indicating greater grit. Prior studies reported Cronbach's alphas of the Grit-S from .73 to .83 in student populations, including pharmacy students. ${ }^{15,55,56}$

The Perceived Stress Scale-10 (PSS-10) is a shortened, validated version of the original Perceived Stress Scale and includes 10 items scored using a Likert scale ranging from $0=$ "never" to $4=$ "very often." 57,58 Four items are reversescored. Total scores range from 0 to 40, with higher scores indicating greater perceived stress. Spivey et al. reported Cronbach's alphas of $.83, .87$, and .89 in administrations of the PSS-10 to P1 students. ${ }^{31}$

The Big Five Inventory (BFI) is a measure of five personality traits: extroversion, agreeableness, conscientiousness, neuroticism, and openness (as previously mentioned, conscientiousness and openness subscale scores were not utilized in this analysis to be parsimonious, as there is a lack of evidence concerning their relationships to academic performance among pharmacy students.). ${ }^{9,59,60}$ The BFI includes 44 items scored on a 5-point Likert scale ranging from $1=$ "disagree strongly" to 5= "agree strongly." Scores were calculated for each subscale/personality trait, with multiple reverse-scored items. Total scores range from 1 to 5, with higher scores indicating greater preference for a given trait. The agreeableness subscale is comprised of nine items, and the extraversion and neuroticism subscales are each comprised of eight items. John et al. ${ }^{60}$ reported Cronbach's alphas of these three subscales ranging from .79 to .87 .

The brief version of Levenson's Locus of Control Scale was used because it attempted to address shortcomings in other versions of commonly used locus of control scales. ${ }^{54}$ Although this scale includes three subscales, this study focused on the Internal Locus of Control subscale based on existing literature among health professions students, suggesting an association between greater internal locus of control and better academic performance. ${ }^{14,19,20}$ Items were scored using a Likert scale ranging from $1=$ "disagree strongly" to 5= "agree strongly." Total scores range from 3 to 15 . Higher scores indicate the individual strongly believes he or she is in control of their own experiences, while lower scores indicate the individual does not tend to believe he or she is in control of their own experiences. Sapp and Harrod ${ }^{54}$ reported Cronbach's alpha of .59 for Internal Locus of Control.

\section{Statistical Analysis}

Data analysis was performed using IBM SPSS Statistics 26.0 and IBM SPSS AMOS 26 (Armonk, New York). Descriptive statistics were calculated to summarize student characteristics, noncognitive factor scores, and GPAs. MannWhitney U tests were performed to determine if significant differences exist between demographic groups (eg, female vs. male, non-Hispanic White vs. minority) based on noncognitive factor scores, pre-pharmacy GPA, and P1 fall GPA. As a total of 16 Mann-Whitney U tests were performed, Bonferroni's adjustment was appropriate (.05 divided by 16), making the alpha level .003.

Structural equation modeling (SEM) was conducted to test/confirm the proposed model (Figure 1). A power analysis (sample size calculation) was conducted using the following parameters: anticipated effect size of .5, desired power level of .8, probability (alpha) level of .05, seven latent variables (noncognitive factors and academic performance), and 48 observed variables (including items which compose the various noncognitive scales, pre-pharmacy GPA, and P1 fall GPA) ${ }^{61,62}$ Minimum sample size required was 366. In the first step of the SEM, bias-corrected bootstrapping was utilized to test for mediation, as a full mediation model (Figure 1) was hypothesized by investigators. ${ }^{63-65}$ The number of bootstrap samples was set at 5000 and bias-corrected confidence interval was set at $95 \% .{ }^{65}$ Bias-corrected bootstrapping assesses the statistical significance of both the direct effect of the relationship between the given noncognitive factor (grit, internal locus of control, agreeableness, extraversion, neuroticism) and academic performance, as well as the indirect effect of the relationship between the given noncognitive factor and academic performance as mediated by perceived stress. Following mediation testing, a model generating scenario was utilized in step two of the SEM in which the proposed model (referred to as Model One) was tested for goodness of fit. ${ }^{66,67}$ As needed, the model was modified and re- 
estimated "to determine a model that better describes the sample data." ${ }^{\text {"66 }}$ A second model (referred to as Model Two) in which P1 fall GPA was the sole indicator of academic performance was also tested to determine consistency and fit of the model when pharmacy school performance alone was considered. To address missing data, the regression imputation method within AMOS was utilized (note, missing data were less than 3\%). The following model fit indices are indicative of good fit: Chi square to degrees of freedom ratio (CMIN/DF) less than 2 (between 2 and 3 is considered adequate); comparative fit index (CFI) greater than 0.95; standardized root mean square residual (SRMR) less than .05; and root mean squared error of approximation (RMSEA) less than .05 (.05 to .08 is considered "close to good"). ${ }^{66,68,69}$ An alpha level of .05 was used to determine statistical significance.

\section{RESULTS}

Among 381 students in the entering classes of 2019 and 2020, seven withdrew from the PharmD program prior to the end of the P1 fall semester and were excluded from the study (remaining in each class: $2019 \mathrm{n}=200$ and $2020 \mathrm{n}=174$ ). (Of note, $43 \%$ of the seven students who withdrew were male, with mean age of 22 [SD=3.73]; six of the seven students completed the survey instruments, and did not significantly differ from study participants on pre-pharmacy GPA or noncognitive scale scores.) Of 200 students in the entering class of 2019, 193 (96.5\%) participated in the study, while all $174(100 \%)$ students in the entering class of 2020 participated, for a total of 367 participants $(98.1 \%$ overall response rate). The majority of participants were female $(\mathrm{n}=238$, or $64.9 \%)$ and non-Hispanic White $(\mathrm{n}=214$, or $58.3 \%)$. Table 2 presents the mean and median GPAs and noncognitive factor scale scores as well as Cronbach's alphas for each scale.

Significant differences $(p=.001)$ in pre-pharmacy GPA were found between non-Hispanic White students $(M=3.42, S D=0.39$, Median=3.46) and minority students $(M=3.29, S D=0.36$, Median=3.29). Significant differences $(p<.001)$ in P1 fall GPA were also found between non-Hispanic White students $(M=3.37, S D=0.52$, Median=3.46) and minority students $(M=3.12, S D=0.57$, Median=3.18). No statistically significant differences in noncognitive scale scores were found based on race/ethnicity. Females had significantly $(p<.001)$ higher scores than males on the following BFI subscales: agreeableness (Female $M=4.36, S D=0.48$, Median=4.44 versus Male $M=4.12, S D=0.6$, Median=4.24); and neuroticism (Female $M=2.9, S D=0.69$, Median=2.88 versus Male $M=2.55, S D=0.8$, Median=2.5). No other statistically significant differences were found based on gender.

Mediation testing of the proposed model (Figure 1) supported that relationships between academic performance and the noncognitive factors of grit, internal locus of control, agreeableness, and extraversion were fully mediated by perceived stress. However, the relationship between neuroticism and academic performance was partially mediated, meaning there was evidence of a direct relationship between the two variables and an indirect relationship mediated by perceived stress. The proposed model was revised to reflect this.

Goodness of fit testing of the full proposed Model One, in which academic performance was indicated by prepharmacy GPA and P1 fall GPA, found that model fit was less than acceptable, with CFI of .75 and SRMR of .08 (although RMSEA and CMIN/DF were acceptable at .06 and 2.34, respectively). To improve fit, the model was modified as follows: grit, agreeableness, and extraversion were removed because they were not significantly associated with perceived stress in the full model ( $p>.05)$. Goodness of fit indices of the modified Model One (Figure 2a) indicated acceptable to good fit: CMIN/DF of 1.82, CFI of .93, SRMR of .05, and RMSEA of .05. Squared multiple correlation of .134 indicated $13.4 \%$ of the variance in academic performance was explained by the predictor variables in the model. The standardized regression weight estimates are displayed in Figure 2a, and unstandardized regression weight estimates are presented in Table 3.

In Model Two, in which academic performance was indicated by P1 fall GPA only, fit of the full model was less than acceptable, with CFI of .75 and SRMR of .08 (although RMSEA and CMIN/DF were acceptable at .06 and 2.39, respectively). Similar to Model One, to improve fit, Model Two was modified as follows: grit, agreeableness, and extraversion were removed because they were not statistically significantly associated with perceived stress in the full model ( $p>.05$ ). Goodness of fit indices of the modified Model Two (Figure 2b) indicated acceptable to good fit: CMIN/DF of 1.97, CFI of .92, SRMR of .05, and RMSEA of .05. Squared multiple correlation of .09 indicated 9\% of the variance in academic performance was explained by the predictor variables in Model Two. The standardized regression weight estimates are displayed in Figure $2 b$, and unstandardized regression weights are presented in Table 3.

\section{DISCUSSION}

The current study is the first of its kind to examine a structural equation model of the associations among the select noncognitive factors and P1 students' academic performance. The final models reveal interesting relationships among the variables. First, the models demonstrate the influence of perceived stress on academic performance, indicating 
higher perceived stress contributes to poorer performance or vice versa (Figure 2). Although some prior studies involving pharmacy students did not find significant associations between perceived stress and academic performance, ${ }^{21,30}$ other studies $^{17,24,25,27,31,32}$ (Table 1) found greater perceived stress is associated with lower GPA, or vice versa, which is consistent with the results of the current study. Perceived stress is therefore a critical target for intervention to support student success. In a systematic review of interventions to decrease perceived stress among graduate students, Stillwell et al. $^{70}$ found evidence that several strategies (often utilized in combination) were effective in reducing perceived stress including training on relaxation skills, breathing and body awareness techniques, time management, mindfulness, meditation, yoga, mindful eating, and controlling negative or irrational thoughts. Such interventions may be of benefit to pharmacy students, and future studies should consider implementation and evaluation of stress management strategies, including effects on academic performance, in this population.

Second, internal locus of control indirectly influenced academic performance via a mediated relationship with perceived stress. Internal locus of control decreased as perceived stress increased (or vice versa); in turn, as perceived stress increased, academic performance decreased (or vice versa). Thus, lower internal locus of control indirectly contributed to poorer academic performance, and likewise higher internal locus of control indirectly contributed to better academic performance. This is consistent with prior studies in the academic nursing and medical literature of the association between internal locus of control and academic performance. ${ }^{14,19,20}$ Prior studies in nursing and undergraduate students suggest several strategies may be utilized and assessed among pharmacy students to improve internal locus of control, which may ultimately reduce stress and/or benefit academic performance. ${ }^{71-73}$ These strategies include problem-based education to encourage problem-solving and self-directed learning; online videos discussing locus of control and growth mindset and how they may be utilized by students during their education; and mentoring programs to build supportive and nurturing connections. ${ }^{71-73}$ For example, Demir et al. ${ }^{71}$ found that a peer mentoring program among nursing students, in which fourth-year students served as mentors for first-year students, contributed to increased internal locus of control and improved ability to cope with stress among the first-year students. These first-year students described their mentors as providing support, motivation, and guidance, which increased self-confidence and self-awareness. ${ }^{71}$

Third, neuroticism both directly and indirectly effected academic performance in the final models. Pertaining to the direct effect, neuroticism was positively associated with academic performance, meaning as neuroticism increased, academic performance increased (or vice versa). Neuroticism also indirectly influenced academic performance via perceived stress as the mediator. To explain further, neuroticism and perceived stress were positively associated, and perceived stress and academic performance were inversely associated. This means higher neuroticism indirectly contributed to decreased academic performance via increased perceived stress (or vice versa). Prior studies of neuroticism in pharmacy students are limited and do not shed much light on the complex relationship with academic performance suggested in this study. ${ }^{22,34}$ In their study of personality traits and academic performance among medical students, Lourinho et al. ${ }^{74}$ found that neuroticism was positively associated $(p=.014)$ with achievement, and suggested, "it is possible that the anxiety component of neuroticism due to its anticipatory ability can have facilitated performance in ... individuals who may have strategically channeled the negative affect to promote high levels of preparation, competitiveness, and striving to attain a better position." However, Lourinho et al. ${ }^{74}$ also caution that high levels of neuroticism may cause greater stress and burnout among health professions students. Consistent with the speculation of Lourinho et al. ${ }^{74}$, we postulate a certain amount of anxiety (neuroticism) is motivating for students, but if that neuroticism becomes overwhelmingly stressful, then academic performance can be negatively impacted. This phenomenon may suggest a healthy and delicate balance of neuroticism and stress is needed for optimal academic performance. To assist in achieving this healthy balance, previous studies suggest mindfulness training may have protective effects for students who score highly on neuroticism. ${ }^{75,76}$ Mentioned earlier as a possible intervention to reduce perceived stress, mindfulness training focuses on improving emotional awareness and developing skills related to emotional regulation, and therefore may assist students in managing anxiety and emotional distress during pharmacy school. Future studies should thus consider the potential role of mindfulness training as a support strategy for pharmacy students.

Among the current study's additional findings, it was interesting to note that no statistically significant differences in noncognitive factor scores were found based on race/ethnicity, although non-Hispanic White students had significantly higher pre-pharmacy GPA and P1 fall GPA. Previous studies are not consistent regarding the relationship between race/ethnicity, pre-pharmacy GPA, and pharmacy school GPA. ${ }^{77,78}$ Additionally, female compared to male students had significantly higher scores on agreeableness and neuroticism, which is consistent with prior studies of gender differences on the Big Five Personality Traits. ${ }^{79,80}$ Given these findings, future studies should consider how the final models function when race/ethnicity and gender are introduced. 
Like all studies, this study has both strengths and limitations. Strengths include a high response rate (greater than 98\%) and the desired sample size indicated in the power analysis, supporting the robustness of the data and analysis, as well as a sample generally representative of the national PharmD student population in terms of gender and race/ethnicity. ${ }^{81}$ However, as noncognitive data were self-reported, response bias may occur in which participants provide answers they believe are preferred by investigators, select the neutral answer option for all or most scale items, or "Agree" or "Disagree" with all or most scale items. ${ }^{82}$ To minimize response bias, participants were assured of confidentiality and provided ample time to read and complete the survey instrument. Additionally, the noncognitive instruments included reverse-scored items that might facilitate greater consideration of the item (due to differences from other items) and disrupt any biased patterns in responses. Another limitation includes the timing of when the survey instruments were distributed. Survey data were collected during the orientation, prior to the start of classes. It is unknown if noncognitive factors may have changed throughout the semester. However, a better understanding of these factors, as measured at a baseline point such as pharmacy school orientation, may be helpful in developing early targeted programming to support student success.

On first glance, an additional limitation is that the variances of the final models may not seem impressive or impactful. However, prior studies have found that standard cognitive measures such as prior GPA and standardized tests predict only approximately $25 \%$ of the variance in pharmacy school GPA. ${ }^{1}$ In that context, these model variances of $9 \%$ and $13 \%$ represent $36 \%$ to $52 \%$ of the predictive value of the most commonly accepted cognitive measures used to assess potential future academic performance. Although a notable portion of the variance in academic performance was explained by the final models, a large percentage remains unexplained, suggesting there are other factors at play in determining student success. Nevertheless, this study represents a critical first step in exploring the effects of perceived stress, grit, internal locus of control, agreeableness, extraversion, and neuroticism on academic performance.

\section{CONCLUSION}

The evidence supports how a framework (structural model) of select noncognitive factors, namely perceived stress, neuroticism, and internal locus of control, affects the academic performance of first-year pharmacy students. Application of this knowledge may be beneficial in admissions, monitoring of academic performance, and developing and implementing programming to support pharmacy student success.

\section{ACKNOWLEDGMENTS}

Marie Chisholm-Burns serves on the board of directors for the Accreditation Council of Pharmacy Education (ACPE). This manuscript does not represent ACPE or the boards' opinions or views.

\section{REFERENCES}

1. Meagher DG, Pan T, Perez CD. Predicting performance in the first-year of pharmacy school. Am J Pharm Educ. 2011;75(5): Article 81. doi: https://doi.org/10.5688/ajpe75581

2. Novovic J, Charrois TL, Cor MK, Hall JJ. Admissions processes in North American pharmacy schools: to what extent are characteristics of practice success measured? Curr Pharm Teach Learn. 2018;10:1550-1564. doi: 10.1016/j.cptl.2018.09.004

3. Stoffel JM, Cain J. Review of grit and resilience literature within health professions education. Am JPharm Educ. 2018;82(2):Article 6150. https://www.ncbi.nlm.nih.gov/pmc/articles/PMC5869747/

4. De Raad, B., \& Schouwenberg, H. C. (1996). Personality in learning and education: A review. European Journal of Personality, 10, 303-336.

5. Lee, J., \& Shute, V. J. (2009). The influence of noncognitive domains on academic achievement in K-12. Educational Testing Service. https://onlinelibrary.wiley.com/doi/abs/10.1002/j.2333-8504.2009.tb02191.x

6. Messick, S. Potential uses of noncognitive measurement in education. Journal of Educational Psychology, 71, 281-292.

7. Gutman, L. M., \& Schoon, I. (2013). The impact of non-cognitive skills on outcomes for young people: Literature review. Education Endowment Foundation. Accessed 3 February 2021. https://www.almendron.com/tribuna/wpcontent/uploads/2018/09/eef-lit-review-non-cognitiveskills.pdf

8. Zhou, K. (2016). Non-cognitive skills: Definitions, measurement, and malleability. United Nations, Educational, Scientific and Cultural Organization. Accessed 3 February 2021. https://unesdoc.unesco.org/ark:/48223/pf0000245576 
9. Chisholm-Burns MA, Berg-Poppe P, Spivey CA, Karges-Brown J, Pithan A. Systematic review of noncognitive factors influence on health professions students' academic performance. Adv Health Sci Educ. 2021. https://doi.org/10.1007/s10459-021-10042-1

10. Hughes BD, Perone JA, Cummins CB, Sommerhalder C, Tyler DS, Bowen-Jallow, KA, Radhakrishnan RS. Personality testing may identify applicants who will become successful in general surgery residency. J Surg Res. 2019;233:240-248.

11. Hulse JA, Chenowith T, Lebedovych L, Dickinson P, Cavanaugh GB, Garrett N. Predictors of student success in the US Army graduate program in anesthesia nursing. AANA J. 2007;75(5):339-346.

12. Kötter T, Wagner J, Brüheim L, Voltmer E. Perceived medical school stress of undergraduate medical students predicts academic performance: an observational study. BMC Med Educ. 2017;17(1):256. doi: 10.1186/s12909017-1091-0

13. Lertwilaiwittaya P, Sitticharoon C, Maikaew P, Keadkraichaiwat I. Factors influencing the National License Examination step 1 score in preclinical medical students. Adv Physiol Educ. 2019;43(3):306-316.

14. Ofori R, Charlton JP. A path model of factors influencing the academic performance of nursing students. $J A d v$ Nurs. 2002;38(5):507-515.

15. Pate AN, Payakachat N, Harrell TK, Pate KA, Caldwell DJ, Franks AM. Measurement of grit and correlation to student pharmacist academic performance. Am J Pharm Educ. 2017;81(6):Article 105. https://www.ncbi.nlm.nih.gov/pmc/articles/PMC5607715/

16. Sobowale K, Ham SA, Curlin FA, Yoon JD. Personality traits are associated with academic achievement in medical school: a nationally representative study. Acad Psychiatry. 2018;42:338-345.

17. Votta RJ, Benau, E. M. Predictors of stress in Doctor of Pharmacy students: results from a nationwide survey. Curr Pharm Teach Learn. 2013;5(5):365-372. https://doi.org/10.1016/j.cptl.2013.06.014

18. Wood AM, Saylor C, Cohen J. Locus of control and academic success among ethnically diverse baccalaureate nursing students. Nurs Educ Perspect. 2009;30(5):290-294.

19. Munro BH. Dropouts from nursing education: Path analysis of a national sample. Nurs Res. 1980;29(6):371-377.

20. Webb CT, Waugh FE, Herbert JD. Relationship between locus of control and performance on the National Board of Medical Examiners, Part 1, among black medical students. Psychol Rep. 1993;72:1171-1177.

21. Alshammari E. Stress profile and university performance of pharmacy students. Int J Res Pharm Sci. 2019;10(4):2647-2653.

22. Azmi N, Ali AM, Wong X-L, Kumolosasi E, Jamal JA, Paraidathatu T. Internal factors affecting academic performance among pharmacy students in Malaysian public institutions of higher learning. Indian J Pharm Educ Res. 2014;48(3):26-33.

23. Dy-Boarman EA, Bottenberg MM, Diehl B, Mobly-Buckstein W, Quaerna B. Lessons learned from an investigation exploring association between grit and student performance in a pharmacy skills laboratory course. Curr Pharm Teach Learn. 2018;10(11):1443-1446.

24. Garber MC, Huston SA, Breese CR. Sources of stress in a pharmacy student population. Curr Pharm Teach Learn. 2019;11:329-337.

25. Geslani GP, Gaebelein CJ. Perceived stress, stressors, and mental distress among Doctor of Pharmacy students. Social Behavior and Personality. 2013;41(9):1457-1468.

26. Gruenberg K, Brock T, MacDougall C. Longitudinal associations between grit, academic outcomes, and residency match rates among pharmacy students. Am J Pharm Educ. 2019;83(6):Article 6947. https://www.ncbi.nlm.nih.gov/pmc/articles/PMC6718489/

27. Kristina SA, Widayanti AW, Sari IP. Investigating perceived stress among final-year pharmacy students in Indonesia. Int J Pharm Res. 2002;12(2):439-444.

28. Palisoc AJL, Matsumoto RR, Ho J, Perry PJ, Tang TT, Ip EJ. Relationship between grit with academic performance and attainment of postgraduate training in pharmacy students. Am J Pharm Educ. 2017;81(4):Article 67. https://www.ncbi.nlm.nih.gov/pmc/articles/PMC5468705/

29. Rothmann S, Basson WD, Rothmann JC. Personality preferences of lecturers and students at a pharmacy school. Int J Pharm Pract. 2000;8(3):225-233.

30. Shin J, Gruenberg K. Test-enhanced learning in a pharmacy therapeutics course. Pharm Educ. 2019;19(1):100107. 
31. Spivey CA, Havrda D, Stallworth S, Renfro C, Chisholm-Burns MA. Longitudinal examination of perceived stress and academic performance of first-year student pharmacists. Curr Pharm Teach Learn, 2020;12(9):11161122. https://doi.org/10.1016/j.cptl.2020.05.002

32. Sun SH, Zoriah A. Assessing stress among undergraduate pharmacy students in University of Malaya. Indian J Pharm Educ Res. 2015;49(2):99-105.

33. Ware KB. Relationship between Myers-Briggs type indicators and NAPLEX performances. Am J Pharm Educ. 2019;83(1), Article 6787. https://www.ncbi.nlm.nih.gov/pmc/articles/PMC6418840/

34. Wolcott M, Lupton-Smith C, Cox WC, McLaughlin JE. A five-minute situational judgment test to assess empathy in first-year student pharmacists. Am J Pharm Educ. 2019;83(6):Article 6960, 1207-1212.

35. Accreditation Council for Pharmacy Education. Accreditation Standards and Key Elements for the Professional Program in Pharmacy Leading to the Doctor of Pharmacy Degree ("Standards 2016"). 2015. https://www.acpeaccredit.org/pdf/Standards2016FINAL.pdf. Accessed February 17, 2021.

36. Chisholm MA. Students performance throughout the professional curriculum and the influence of achieving a prior degree. Am J Pharm Educ. 2001;65:350-354.

37. Clavier CW. Academic performance of first-year students at a college of pharmacy in East Tennessee: Models for prediction (Doctoral dissertation). 2013. https://dc.etsu.edu/cgi/viewcontent.cgi?article=2267\&context=etd. Accessed February 19, 2021.

38. Houglum JE, Aparasu RR, Delfinis TM. Predictors of academic success and failure in a pharmacy professional program. Am J Pharm Educ. 2005;69(3):Article 43, 283-289. http://archive.ajpe.org/aj6903/aj690343/aj690343.pdf

39. Meagher DG, Lin A, Stellato CP. A predictive validity study of the Pharmacy College Admission Test. Am J Pharm Educ. 2006;70:Article 53.

1. https://www.ncbi.nlm.nih.gov/pmc/articles/PMC1636944/

40. American Psychological Association. Big Five personality model. APA Dictionary of Psychology. 2020. https://dictionary.apa.org/big-five-personality-model. Accessed February 19, 2021.

41. Jerant A, Griffin E, Rainwater J. Does applicant personality influence multiple mini-interview performance and medical school acceptance offers? Acad Med. 2012;87(9):1250-1259.

42. Trapmann S, Hell B, Hirn J-OW, Schuler H. Meta-analysis of the relationship between the big five and academic success at university. Zeitschrift für Psychologie. 2007; 215(2):132-151.

43. Duckworth AL, Peterson C, Matthews MD, Kelly DR. Grit: perseverance and passion for long-term goals. $J$ Personal Soc Psychol. 2007;92(6):1087-1101. https://doi.org/10.1037/0022-3514.92.6.1087

44. Jha K, Kumar Y, Kumar T, Singh R, Dubey P. Role of language proficiency and personality traits upon the academic performance of undergraduate medical students. J Educ Health Promot. 2019;8:260. https://www.ncbi.nlm.nih.gov/pmc/articles/PMC6967238/

45. Phillips AC. Perceived stress. In: Gellman MD, Turner JR, eds. Encyclopedia of Behavioral Medicine. 2013. Springer. https://link.springer.com/referenceworkentry/10.1007\%2F978-1-4419-1005-9_479

46. Hopwood CJ. Moderation and mediation in structured equation modeling: applications for early intervention research. Journal of Early Intervention. 2007;29(3):262-272.

47. Lazarus RS, Folkman S. Stress, Appraisal, and Coping. New York: Springer; 1984.

48. Chisholm, M. A., Cobb, H. H. III, \& Kotzan, J. A. Significant factors for predicting academic success of first-year pharmacy students. Am J Pharm Educ. 1995;59(4):364-370.

2. https://pdfs.semanticscholar.org/3e6b/5e1b22630abbd5c25f7620a72b2709ce928f.pdf

49. Chisholm, M. A., Cobb, H. H. III, Kotzan, J. A., \& Lautenschangler, G. Prior four year college degree and academic performance of first year pharmacy students: a three year study. Am J Pharm Educ. 1997;61(3):278281.

50. Cor MK, Brocks DR. Examining the relationship between prerequisite grades and types of academic performance in pharmacy school. Curr Pharm Teach Learn. 2018;10(6):695-700. doi: https://doi.org/10.1016/j.cptl.2018.03.008

51. Schauner S, Hardinger KL, Graham MR, Garavalia L. Admission variables predictive of academic struggle in a PharmD program. Am J Pharm Educ. 2013;77(1):Article 8.

3. https://www.ncbi.nlm.nih.gov/pmc/articles/PMC3578340/pdf/ajpe7718.pdf 
52. Džubur A, Lisica D, Abdulahović D, Ejubović M. Impact of social and psychological factors on academic achievement of university students. Medicinski Glasnik. 2020;17. Retrieved from http://ljkzedo.ba/mgpdf/mg32/21_Dzubur_1080_A.pdf

53. Bland J, Altman D. Statistics notes: Cronbach's alpha. BMJ,1997;314: 275. doi:

4. https://doi.org/10.1136/bmj.314.7080.572

54. Sapp SG, Harrod WJ. Reliability and validity of a brief version of Levenson's locus of control scale. Psychol Rep,1993;72:539-550.

55. Duckworth AL, Quinn PD. Development and validation of the Short Grit Scale (Grit-S). J Personal Assess. 2009;91:166-174.

56. Chisholm-Burns MA, Spivey CA, Sherwin E, Williams J, Phelps SJ. Development of an instrument to measure academic resilience among pharmacy students. Am J Pharm Educ. 2019;83(6):Article 6896. https://www.ncbi.nlm.nih.gov/pmc/articles/PMC6718499/

57. Cohen S, Williamson G. Perceived stress in a probability sample of the United States. In Spacapan S, Oskamp S, eds. The Social Psychology of Health: Claremont Symposiumon applied social psychology. Newbury Park, CA: Sage; 1988:31-67.

58. Roberti JW, Harrington LN, Storch EA. Further psychometric support for the 10-item version of the Perceived Stress Scale. Journal of College Counseling, 2006;9:135-147.

59. John OP, Naumann L, Soto CJ. Paradigm shift to the integrative Big Five taxonomy: History, measurement, and conceptual issues. In: John OP, Robins RW, Pervin LA, eds. Handbook of Personality: Theory and Research. 3rd ed. New York: Guilford; 2008:114-158.

60. John OP, Srivastava S. The Big-Five trait taxonomy: History, measurement, and theoretical perspectives. In: Pervin LA, John OP, eds. Handbook of Personality: Theory and Research. Vol. 2. New York: Guilford Press; 1999:102-138.

61. Soper DS. A-priori sample size calculator for structural equation models [Software]. 2020. http://www.danielsoper.com/statcalc. Accessed February 19, 2021.

62. Westland JC. Lower bounds on sample size in structural equation modeling. Electronic Commerce Research and Applications, 2010;9(6):476-487.

63. Fritz MS, MacKinnon DP. Required sample size to detect the mediated effect. Psychol Sci, 2007;18: 233-239.

64. Shrout PE, Bolger N. Mediation in experimental and nonexperimental studies: new procedures and recommendations. Psychol Methods, 2002;7:422-445.

65. Woody E. An SEM perspective on evaluating mediation: What every clinical researcher needs to know. $J$ Exp Psychopathol, 2011;2(2):210-251.

66. Byrne BM. Structural Equation Modeling with Amos. Basic Concepts, Applications, and Programming. $3^{\text {rd }}$ ed. New York: Routledge; 2016.

67. Jöreskog KG. Testing structural equation models. In: Bollen KA, Long JS, eds. Testing Structural Equation Models. Newbury Park, CA: Sage; 1993:294-316.

68. Carmines EG, McIver JP. Analyzing models with unobserved variables. In: Bohrnstedt GW, Borgatta EF, eds. Social Measurement: Current Issues. Newbury Park, CA: Sage; 1981.

69. Marsh HW, Hocevar, D. Application of confirmatory factor analysis to the study of self-concept: first- and higher-order factor models and their invariance across groups. Psychol Bull. 1985;97:562-582.

70. Stillwell SB, Vermeesch AL, Scott JG. Interventions to reduce perceived stress among graduate students: a systematic review with implications for evidence-based practice. Worldviews Evid Based Nurs. 2017;14(6):507513. doi: 10.1111/wvn. 12250

71. Demir S, Demir SG, Bulut H. Effect of mentoring program on ways of coping with stress and locus of control for nursing students. Asian Nurs Res. 2014;8(4):254-260. doi: 10.1016/j.anr.2014.10.004

72. Günüşen NP, Serçekuş P, Edeer AD. A comparison of problem-based and traditional education on nursing students' locus of control and problem-solving skills. Int J Nurs Knowl. 2014;25(2):110-115. doi: 10.1111/20473095.12024

73. Nallapothula D, Lozano JB, Han S, Herrera C, Sayson HW, Levis-Fitzgerald M, Maloy J. M-LoCUS: a scalable intervention enhances growth mindset and internal locus of control in undergraduate students in STEM. J Microbiol Biol Educ. 2020;21(2):21.2.46. doi: 10.1128/jmbe.v21i2.1987 
74. Lourinho I, Ferreira MA, Severo M. Personality and achievement along medical training: evidence from a crosslagged analysis. PLoS One. 2017;12(10):e0185860. https://doi.org/10.1371/journal.pone.0185860

75. de Vibe M, Solhaug I, Tyssen R, Friborg O, Rosenvinge JH, Sørlie T, Halland E, Bjørndal A. Does personality moderate the effects of mindfulness training for medical and psychology students? Mindfulness. 2015;6:281-289.

76. Iani L, Lauriola M, Cafaro V, Didonna F. Dimensions of mindfulness and their relations with psychological wellbeing and neuroticism. Mindfulness. 2017;8:664-676.

77. Chisholm-Burns MA, Spivey CA, Byrd DC, McDonough SLK, Phelps SJ. Examining the association between the NAPLEX, Pre-NAPLEX, and pre-and post-admission factors. Am J Pharm Educ. 2017;81(5):Article 86. https://www.ncbi.nlm.nih.gov/pmc/articles/PMC5508085/pdf/ajpe81586.pdf

78. Schlesselman LS, Coleman CI. Predictors of poor student performance at a single, Accreditation Council for Pharmacy Education-accredited school of pharmacy. Curr Pharm Teach Learn. 2011;3(2):101-105. doi: https://doi.org/10.1016/j.cptl.2011.01.002

79. Giolla EM, Kajonius, PJ. Sex differences in personality are larger in gender equal countries: replicating and extending a surprising finding. Int J Psychol. 2018;54:705-711. https://doi.org/10.1002/ijop.12529

80. Weisberg YJ, DeYoung CG, Hirsch JB. Gender differences in personality across the ten aspects of the Big Five. Front Psychol. 2011;2:178. doi: 10.3389/fpsyg.2011.00178

81. American Association of Colleges of Pharmacy. 2018-19 profile of pharmacy students. https://www.aacp.org/sites/default/files/2020-05/fall-2019-pps-enrollments.pdf. Accessed April 13, 2021.

82. Johnson C. Understanding the 6 types of response bias (with examples). Nextiva. https://www.nextiva.com/blog/response-bias.html. Accessed February 19, 2021. 
Figure 1. Proposed Model of the Relationships among Select Noncognitive Factors and Academic Performance

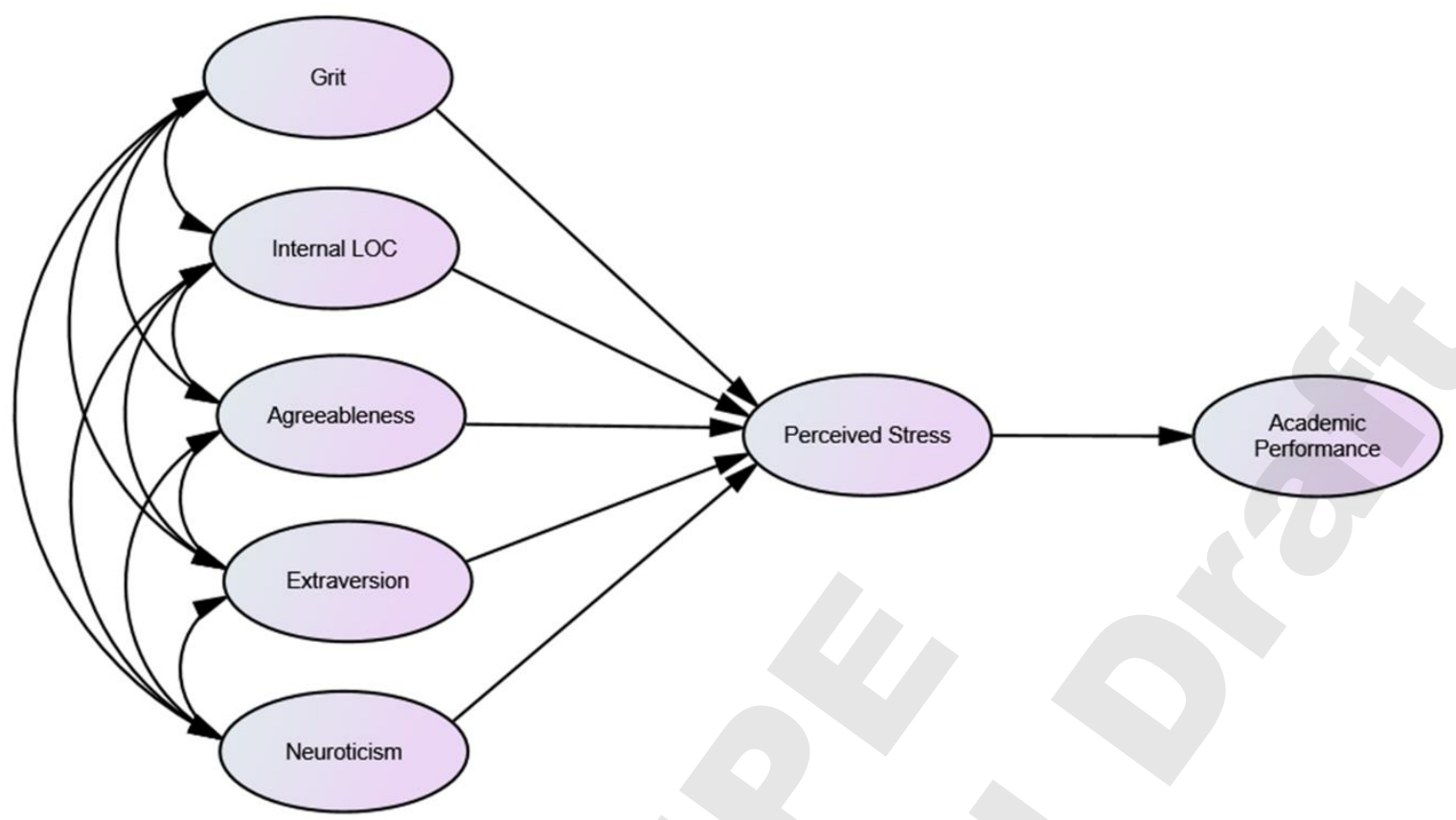

Figure 1. Proposed Model of the Relationships among Select Noncognitive Factors and Academic Performance. The figure displays the proposed model of relationships among academic performance (as indicated by pre-pharmacy grade point average [GPA] and first-year fall GPA) and the noncognitive factors of grit, internal locus of control (LOC), and select Big Five Personality Traits (agreeableness, extraversion, and neuroticism), as mediated by perceived stress. Hypothesized associations (relationships) among the independent variables are represented by bidirectional arrows, and relationships among the independent variables (noncognitive factors) and dependent variable (academic performance) are represented by unidirectional arrows. 
Figure 2. Modified Models One and Two of the Relationships among Select Noncognitive Factors and Academic Performance

\section{2a. Modified Model One}

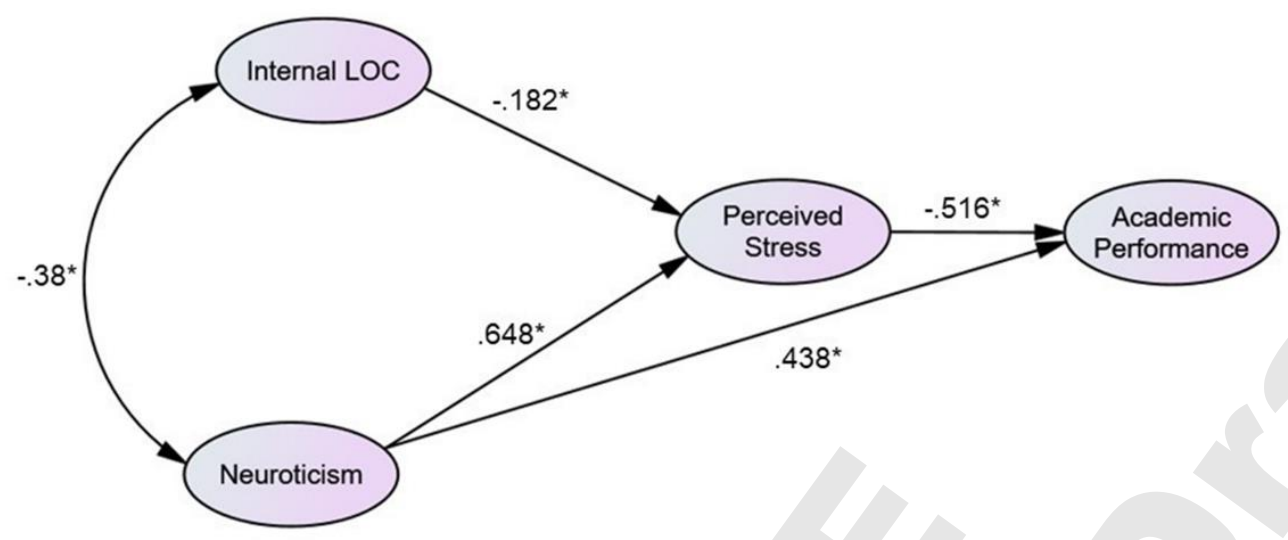

2b. Modified Model Two

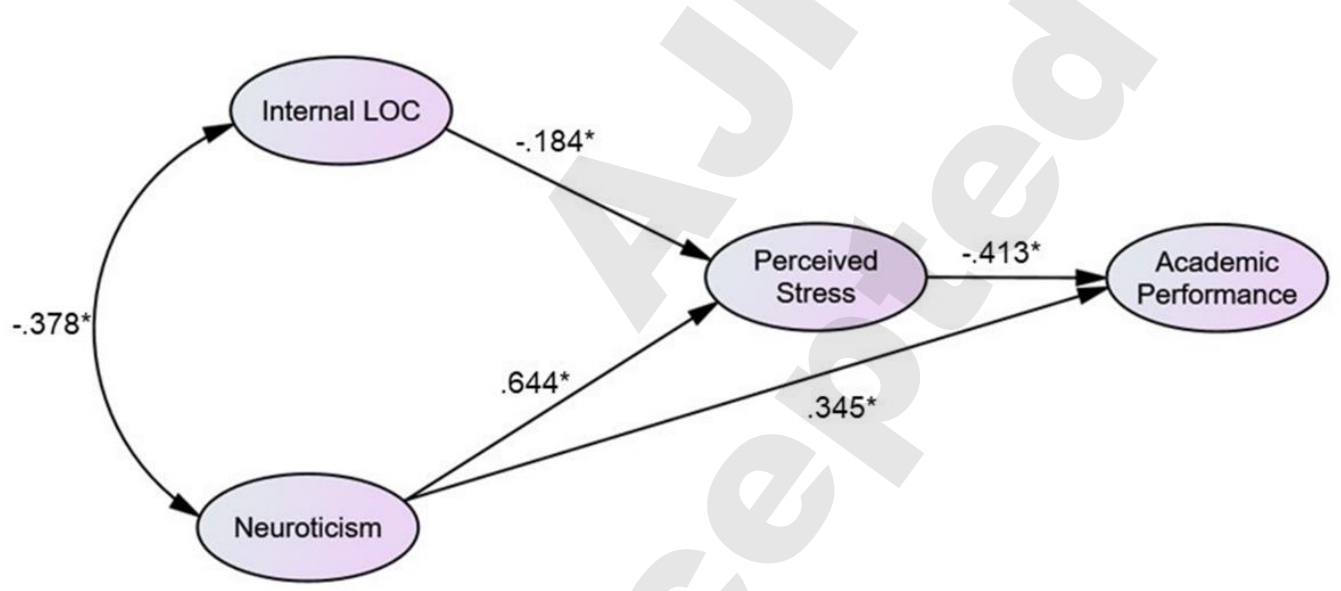

Figure 2. Modified Models One and Two of the Relationships among Select Noncognitive Factors and Academic Performance. Figure 2a displays the standardized regression weight estimates for Modified Model One (in which academic performance was indicated by pre-pharmacy GPA and P1 fall GPA), as well as the correlation between internal locus of control (LOC) and neuroticism. Figure $2 \mathrm{~b}$ displays the standardized regression weight estimates for Modified Model Two (in which academic performance was indicated by P1 Fall GPA only), as well as the correlation between internal LOC and neuroticism. GPA, grade point average. ${ }^{*} p<.05$ 
Table 1. Studies $(n=16)$ of the Relationships Between Select Noncognitive Factors and Academic Outcomes in Pharmacy Students ${ }^{\mathrm{a}}$

\begin{tabular}{|c|c|c|}
\hline Study & $\begin{array}{c}\text { Noncognitive } \\
\text { Factor(s) }\end{array}$ & Findings \\
\hline $\begin{array}{l}\text { Alshammari } \\
(2019)^{21}\end{array}$ & Perceived Stress & $\begin{array}{l}\text { No significant correlations were noted between indicators of stress } \\
\text { and GPA ( } n=240 \text { participants). }\end{array}$ \\
\hline $\begin{array}{l}\text { Azmi et al. } \\
(2014)^{22}\end{array}$ & $\begin{array}{c}\text { Conscientiousness, } \\
\text { Extraversion, } \\
\text { Neuroticism }\end{array}$ & $\begin{array}{l}\text { In a sample of } 1018 \text { students, neuroticism and GPA were } \\
\text { significantly, but weakly correlated (Spearman rho= }-.076 \text {, } \\
p=.015) \text {; however, conscientiousness and extraversion were not } \\
\text { significantly correlated with GPA. }\end{array}$ \\
\hline $\begin{array}{l}\text { Dy-Boarman et } \\
\text { al. }(2018)^{\text {a, } 23}\end{array}$ & Grit & $\begin{array}{l}\text { No significant differences were found in total grit score between } \\
\text { students who passed all components of a laboratory practical } \\
\text { examination on the first attempt and those requiring } \\
\text { remediation/re-examination ( } n=163 \text { participants). }\end{array}$ \\
\hline $\begin{array}{l}\text { Garber et al. } \\
(2019)^{24}\end{array}$ & Perceived Stress & $\begin{array}{l}\text { In a sample of } 352 \text { students, greater stress was significantly } \\
\text { associated with lower GPA }(p=.015) \text {. }\end{array}$ \\
\hline $\begin{array}{l}\text { Geslani \& } \\
\text { Gaebelein } \\
(2013)^{25}\end{array}$ & Perceived Stress & $\begin{array}{l}\text { In a sample of } 139 \text { students, those with a GPA } \leq 3.0 \text { had } \\
\text { significantly higher stress than those with a GPA }>3.0(p<.04) \text {. }\end{array}$ \\
\hline $\begin{array}{l}\text { Gruenberg et al. } \\
(2019)^{26}\end{array}$ & Grit & $\begin{array}{l}\text { Grit was not significantly associated with GPA, APPE evaluation, } \\
\text { or ASHP residency match }(n=852 \text { participants). }\end{array}$ \\
\hline $\begin{array}{l}\text { Kristina et al. } \\
(2020)^{27}\end{array}$ & Perceived Stress & $\begin{array}{l}\text { In a sample of } 330 \text { students, those with a GPA }>3.5 \text { reported } \\
\text { significantly greater stress than students witha GPA }<3.0(\mathrm{OR}= \\
1.32,95 \% \mathrm{CI}=1.03,2.23) \text {; however, stress level was not } \\
\text { significantly different between students with a GPA of } 3 \text { to } 3.5 \text { vs. } \\
<3.0 \text {. }\end{array}$ \\
\hline
\end{tabular}

In a sample of 98 students, total grit score and academic success, defined as GPA $\geq 3.0$ and no course failure, were not significantly correlated; however, total grit score was significantly associated

Palisoc et al. $(2017)^{28}$

Grit with attaining postgraduate training $(\mathrm{OR}=34.6,95 \% \mathrm{CI}=2.5$, 482.8).

In a sample of 724 students, higher total grit score was significantly associated with GPA $\geq 3.5$ vs. GPA 3.0 to $3.49(\mathrm{RR}=$ $1.8,95 \% \mathrm{CI}=1.5,2.3)$, but was not significantly associated with GPA $<3.0$ vs. GPA 3.0 to 3.49 . There were no significant Pate et al. $(2017)^{15}$

Grit differences in total grit score between students who reported no grades of D or F vs. those who reported having D or F grades.

Introversion was significantly, moderately correlated with academic performance among P4 students ( $r=.34$ to $.47, p$ value not reported), but extraversion/introversion was not significantly

Rothmann et al. Extraversion/ correlated with academic performance among P1-P3 students $(2000)^{29}$ Introversion ( $n=603$ participants).

Shin \&

Gruenberg $(2019)^{30}$

Perceived Stress

In a sample of 243 students, stress was not significantly associated with changes in therapeutics course test scores.

Spivey et al. $(2020)^{31}$

Perceived Stress

Stress score (measured in P1 spring semester, $\mathrm{n}=110$ ) was significantly, weakly correlated $(p<.05)$ with P1 fall GPA $(r=-.2)$, 
Sun \& Zoriah

$(2015)^{32}$

Perceived Stress

Votta \& Benau $(2013)^{17}$

Perceived Stress

Ware (2019) $)^{33}$

Extraversion

All Big Five

Wolcott et al. $(2019)^{34}$
P1 spring GPA ( $r=-.24)$, and P1 year GPA ( $r=-.22)$. In multiple linear regression analysis $(n=201)$, stress score (measured at beginning of P1 year) was significantly associated with P1 year GPA $(p=.006)$.

In a sample of 273 students, stress and GPA were significantly, but weakly correlated $(r=-.159, p=.009)$.

In a sample of 2232 students, those with a GPA 2.0 to 2.49 had significantly higher stress than students with a GPA 3.0 to 3.49 and 3.5 to $4.0(p<.001)$; however, there were no significant differences in stress levels between students with a GPA 2.0 to 2.49 and 2.5 to 2.99. Students with a GPA 2.5 to 2.99 had significantly higher stress than students with a GPA 3.0 to 3.49 and 3.5 to $4.0(p<.001)$. There were no significant differences in stress levels between students with a GPA 3.0 to 3.49 and 3.5 to 4.0. Students with a GPA $\leq 2.99$ had significantly greater stress than students with a $\mathrm{GPA} \geq 3.0(p<.001)$

In a sample of 119 students, those with extraversion personality scored 9.5 points lower on NAPLEX compared to those with introversion personality $(t=3.5, p<.01,95 \% \mathrm{CI}=4.2-14.9)$

In a sample of 135 students, agreeableness and situational judgment test (SJT) performance were significantly, but weakly correlated ( $r=-.21$ to $-.16, p<.05)$. The remaining Big Five Personality Traits were not significantly correlated with SJT performance.

APPE, advanced pharmacy practice experience; ASHP, American Society of Health-System Pharmacists; CI, confidence interval; GPA, grade point average; NAPLEX, North American Pharmacist Licensure Examination; NCD, not clearly defined; OR, odds ratio; P1, first-year pharmacy; P3, third-year pharmacy; P4, fourth-year pharmacy; RR, relative risk

${ }^{a}$ For each study in the table, we present the number of students who participated in or completed the study, ie, final sample size.

${ }^{\mathrm{b}}$ Dy-Boarman et al. note their study had design limitations that may interfere with the interpretation of results.

${ }^{c}$ Big Five Personality Traits: agreeableness, conscientiousness, extraversion, neuroticism, openness 
Table 2. Summary of Demographics, Pre-pharmacy GPA, First-Year (P1) Fall GPA, and Noncognitive Factor Scores of Participants in the Entering Classes of 2019 and 2020

\begin{tabular}{|c|c|}
\hline & $\begin{array}{c}\text { Participants } \\
(\mathrm{n}=367)\end{array}$ \\
\hline \multicolumn{2}{|l|}{ Gender } \\
\hline Female, n (\%) & $238(64.9)$ \\
\hline Male, n (\%) & $126(34.3)$ \\
\hline Other & $3(0.8)$ \\
\hline \multicolumn{2}{|l|}{ Race/Ethnicity } \\
\hline Non-Hispanic White, n (\%) & $214(58.3)$ \\
\hline Minority $^{\mathrm{a}}, \mathrm{n}(\%)$ & $151(41.1)$ \\
\hline Missing & $2(0.5)$ \\
\hline \multicolumn{2}{|l|}{ Pre-pharmacy GPA } \\
\hline Mean (SD) & $3.37(0.39)$ \\
\hline Median (IQR) & $3.37(0.59)$ \\
\hline \multicolumn{2}{|l|}{ P1 Fall GPA } \\
\hline Mean (SD) & $3.27(0.56)$ \\
\hline Median (IQR) & $3.34(0.75)$ \\
\hline \multicolumn{2}{|l|}{ BFI Agreeableness Score } \\
\hline Mean (SD) & $4.28(0.53)$ \\
\hline Median (IQR) & $4.33(0.67)$ \\
\hline Cronbach's alpha & 0.74 \\
\hline \multicolumn{2}{|l|}{ BFI Extraversion Score } \\
\hline Mean (SD) & $3.34(0.84)$ \\
\hline Median (IQR) & $3.33(1.25)$ \\
\hline Cronbach’s alpha & 0.85 \\
\hline \multicolumn{2}{|l|}{ BFI Neuroticism Score } \\
\hline Mean (SD) & $2.78(0.75)$ \\
\hline Median (IQR) & $2.75(1)$ \\
\hline Cronbach’s alpha & 0.81 \\
\hline \multicolumn{2}{|l|}{ Grit-S Score } \\
\hline Mean (SD) & $3.75(0.55)$ \\
\hline Median (IQR) & $3.8(0.73)$ \\
\hline Cronbach's alpha & 0.74 \\
\hline \multicolumn{2}{|l|}{ Internal Locus of Control Score } \\
\hline Mean (SD) & $12.4(1.96)$ \\
\hline Median (IQR) & $13(3)$ \\
\hline Cronbach's alpha & 0.62 \\
\hline \multicolumn{2}{|l|}{ Perceived Stress Scale-10 Score } \\
\hline Mean (SD) & $16.25(5.92)$ \\
\hline Median (IQR) & $16(8)$ \\
\hline Cronbach's alpha & 0.85 \\
\hline
\end{tabular}

a"Minority" is defined as any student who identified as non-White and/or Hispanic.

BFI, Big Five Inventory; GPA; grade point average; Grit-S, Short Grit Scale; IQR, interquartile range (a measure of variability defined as the difference between the midpoints of the third quartile [upper quarter] and first quartile [lower quarter] of data) 
Table 3. Unstandardized Regression Weight Estimates and Standard Errors of Modified Models One and Two of the Relationships among Noncognitive Factors and Academic Performance (as indicated by Pre-Pharmacy GPA and P1 Fall GPA in Model One and P1 Fall GPA only in Model Two)

\begin{tabular}{lccc}
\hline Relationship & Estimate & Standard Error & $\boldsymbol{p}$ value \\
\hline Modified Model One & & & \\
$\quad$ Perceived Stress-Internal Locus of Control & -.199 & .066 & .003 \\
Perceived Stress-Neuroticism & .501 & .055 & $<.001$ \\
Academic Performance-Perceived Stress & -.114 & .049 & .02 \\
Academic Performance-Neuroticism & .075 & .034 & .03 \\
Modified Model Two & & & \\
$\quad$ Perceived Stress-Internal Locus of Control & -.201 & .066 & .002 \\
Perceived Stress-Neuroticism & .500 & .055 & $<.001$ \\
Academic Performance-Perceived Stress & -.309 & .071 & $<.001$ \\
Academic Performance-Neuroticism & .200 & .056 & $<.001$ \\
\hline
\end{tabular}

GPA, grade point average 


\section{Appendix A}

Pre-Pharmacy Prerequisite Coursework

$\underline{\text { Science Courses }}$

General Chemistry

2 courses 8 semester hours

Organic Chemistry

2 courses $\quad 8$ semester hours

General Biology/Zoology 2 courses 8 semester hours

Microbiology 1 course 3 semester hours

Anatomy-Physiology 2 courses 8 semester hours

Mathematics Courses

Calculus $\quad 1$ course 3 semester hours

Statistics 1 course 3 semester hours

Communications Courses

English Composition

2 courses 6 semester hours

Communications/Speech $\quad 1$ course 3 semester hours

\section{Elective Courses}

Elective courses must conform to the following distribution and requirements

- At least two (2) courses totaling 6 semester hours must be taken in the Humanities (including, but not limited to: arts, literature, history, language, philosophy).

- At least two (2) courses totaling 6 semester hours must be taken in the Social Sciences (including, but not limited to: sociology, psychology, anthropology, political science, economics).

From: University of Tennessee Health Science Center College of Pharmacy. Prerequisite coursework.

https://www.uthsc.edu/pharmacy/prospective-students/admissions/prereqcoursework.php 


\section{Appendix B}

First-year Fall Semester Courses of the Doctor of Pharmacy Program

\begin{tabular}{lc}
\multicolumn{1}{c}{ Courses } & Credit \\
\hline Biochemistry (PHCY 1100) & 2.5 \\
Fundamentals of Drug Action (PHCY 1101) & 2 \\
Pharmacy Math (PHCY 1102) & 1 \\
Foundations of Pharmacy (PHCY 1104) & 2.5 \\
Interprofessional Education \& Clinical Simulation (IPECS) I (PHCY & 2 \\
1105) & - \\
IPPE I: Introduction to Patient Care (PHCY 1106) & 1 \\
Pharmacy Professional Development I (PHCY 1107) & 2 \\
Self Care and Dermatology (PHCY 1111) & 2.5 \\
Introduction to Therapeutics (PHCY 1109) & 3 \\
Dosage Design, Delivery, and Dispensing (D4) I (PHCY 1110) & - \\
Recitation & \\
Totals & $\mathbf{1 8 . 5}$ \\
\hline
\end{tabular}

